\title{
The control of attention by abrupt visual onsets and offsets
}

\author{
JEFF MILLER \\ University of California, San Diego, La Jolla, California
}

\begin{abstract}
A letter can be presented visually either by the abrupt appearance of lines that make up the letter (onset transient) or by the abrupt disappearance of extra lines from a form in which the letter is embedded (offset transient). Recent evidence from visual-search tasks has suggested that onset transients have absolute priority over offset transients with respect to the allocation of visual attention. Specifically, these studies have found that a single onset-transient target letter pops out of a background of offset-transient distractor letters (i.e., time to detect the target is independent of the number of distractors), which indicates that attention is automatically directed to the location of an onset-transient stimulus even when there are competing offset transients (Yantis \& Jonides, 1984). Because of the way the offset letters were created, however, the total display change (number of offset line-segments plus number of onset line-segments) was greater for onset than for offset letters. Thus, onset targets might have popped out because they produced greater overall display changes rather than because they were the only letters with onset transients. In the present study, a figure that included more offset-transient line segments in the offset-transient letters was used. Under these conditions, onset-transient targets did not pop out of a background of offset-transient distractors. It is suggested that visual attention may be influenced by total display change and, therefore, that onset transients are not necessarily sufficient to control attention when there are many competing offset transients.
\end{abstract}

It is quite clear that attention to a visual location can facilitate detecting, identifying, and responding to whatever stimulus is presented there (e.g., Johnston \& Dark, 1986). This basic fact has generated an extended debate about the level(s) in visual processing at which attention has its effect(s) (see Duncan, 1981; Kahneman \& Treisman, 1984). A question of somewhat more practical importance for the design of visual displays, however, is what controls the allocation of attention to particular locations in visual space.

To a large extent, visual attention is controlled voluntarily (e.g., James, 1890), and the mechanisms for this type of attentional control have been studied extensively (e.g., Eriksen \& Hoffman, 1972; Shaw \& Shaw, 1977). Less consideration has been given to the control of attention by factors external to the perceiver, although it is clear that attention is influenced by such factors as stimulus configuration (Bartram, 1978), objectness (Duncan, 1984), and task demands (e.g., LaBerge, 1983).

Abrupt changes in the visual field (i.e., visual transients) seem to have some of the strongest effects on visual attention of any external factors (e.g., Breitmeyer \& Ganz, 1976; Hoffman, Nelson, \& Houck, 1983). Yantis and

This research was supported by Grant PHS-MH40733 from the National Institute of Mental Health. I would like to thank Grace Fang for assistance in testing the subjects, and Patricia Haden, David Phillips, and Steven Yantis for helpful comments on the manuscript. Correspondence should be addressed to Jeff Miller, Department of Psychology, C-009, University of California, San Diego, La Jolla, CA 92093.
Jonides (1984) have provided an excellent review of the evidence from a variety of domains that supports this claim. For example, Jonides (1981) showed that attention can be directed to a given location much faster and more effortlessly by a peripheral flash in that location than by a central cue to the location.

Given that attention is attracted by abrupt changes in the visual field, it is natural to ask whether attention responds both to abruptly appearing stimuli (onset transients) and to abruptly disappearing stimuli (offset transients). In principle, attention might be attracted either by onset transients only, by offset transients only, or by both types of transients (i.e., to any change in the visual field). Several psychophysical studies have found that people are very sensitive to both types of transients (e.g., Phillips \& Singer, 1974; Stelmach, Bourassa, \& Di Lollo, 1984), and there is evidence of separate single units that respond independently to the two types of transients in the lateral geniculate nucleus (e.g., Schiller, 1984). Based on these findings, one might expect that onset and offset transients would both attract visual attention effectively.

However, Yantis and Jonides (1984) have concluded that onset transients are much more powerful attention attractors than are offset transients. In that study, a visualsearch task was used, in which subjects were asked to indicate the presence or absence of a target letter as soon as possible after presentation of a visual display that contained either two or four letters. One letter was always presented as an onset transient; this letter appeared sud- 
denly in what had previously been a blank area of the display. The other letter(s) in the display were presented as offset transients. Specifically, these letters appeared when lines were removed from a figure-8 premask (see Figure 1A) which had previously been presented in that area of the display. The letters $E, H, P, S$, and $U$ were used as stimuli, so that all stimuli could be created by removing lines from this premask.

Yantis and Jonides (1984) found that when the target was the only onset-transient letter in the visual display, the number of offset-transient distractors had no effect on target-detection time. This finding suggests that attention is automatically directed toward onset transients even when several offset transients are present in the display. In this situation, attentional capture caused the onsettransient letter to be examined first, thus preventing any effect of offset-transient distractors. In more recent work, Jonides and Yantis (1988) also found that onset transients seem unique in their ability to command attentional responses. Specifically, they found that the display-size effect was not eliminated when targets were different from distractors in brightness or color, rather than in the presence of onset transients.

The finding that onsets dominate offsets in attentional capture is suggestive about the neural mechanisms that subserve attentional control. This finding indicates that the activity of onset detectors gates out the offset detectors. Therefore, these results cannot be reconciled with a model in which these two types of detectors have independent (though not necessarily equal) inputs into the mechanism that controls attention.

Before accepting an interactive model, however, it should be noted that the experiments of Yantis and Jonides (1984) contain a confound that may have contributed to the dominance of onset transients in their subjects. Specifically, the stimuli used in the onset condition appear to have produced a much larger total visual change (num-
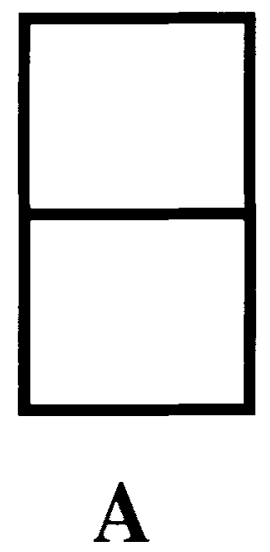
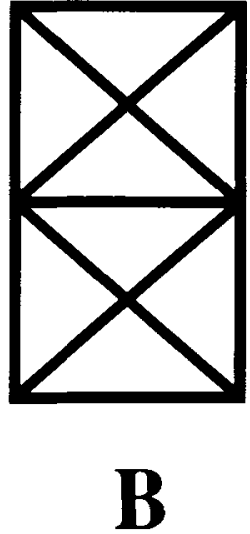

Figure 1. The letters E, F, H, S, and U can be revealed by removing lines (offset transients) from these premask figures. In such a display these letters are presented with only offset transients. Premask A was used by Yantis and Jonides (1984) and in Experiment 2 of the present paper. Premask B was used in Experiment 1 of the present study. ber of offsets plus number of onsets) than those used in the offset condition. Based on the results of Rumelhart $(1970,1971)$, it seems reasonable to regard the premask as an amalgamation of seven line segments. Each of the offset letters can be made by removing only two of the segments from the premask, whereas each onset stimulus requires the addition of five line-segments to the display. Thus, the total number of line segments that changed state (on vs. off) was considerably larger for onset stimuli than for offset stimuli. ${ }^{1}$

The purpose of the experiments reported here was to investigate the importance of this overall change confound. In Experiment 1, the premask was augmented as shown in Figure 1B. If onsets can dominate any number of offsets, then popout (detection of the onset target independent of the number of detractors) should occur even with this augmented premask. If total display change is a factor and onsets do not automatically dominate offsets, then popout nay disappear with this premask due to the increase in the number of offset transients. ${ }^{2}$

\section{EXPERIMENT 1}

This experiment was modeled closely after the visualsearch task used in Experiment 1 of Yantis and Jonides (1984). At the beginning of each trial, subjects were shown a single target letter. They were subsequently shown a test display of two or four letters, and they pressed one response key if the target was present in the test display and another key if it was not present. One letter in the test display was always presented as an onset transient, and the other one or three letters were presented by removing lines from a premask (offset transients). The major change from the procedure of Yantis and Jonides (1984) was the use of the premask shown in Figure 1B, rather than the premask shown in Figure $1 \mathrm{~A}$, in order to produce a greater display change with offset-transient letters.

\section{Method}

Subjects. The subjects were 34 undergraduates at the University of California, San Diego, whose participation was in partial fulfillment of a course requirement. Two subjects were eliminated for responding at chance levels, and 1 subject's data were lost because of computer malfunction.

Stimuli. The stimuli were presented and responses and response latencies were recorded by an IBM PC-compatible computer equipped with an enhanced graphics adapter and attached to an NEC Multisync display monitor. The subjects viewed the display from a distance of about $60 \mathrm{~cm}$, and responses were made by pressing the $Z$ and / (slash) keys on the standard computer keyboard with their left and right index fingers.

The stimuli were the upper case letters $E, H, P, S$, and $U$, each of which could be made by deleting lines from the premask. Because of concern with the exact stimulus parameters, two different sizes of letters and premasks were used. The large letters were $4.6^{\circ}$ high and $2.4^{\circ}$ wide, and the small ones were $2.1^{\circ}$ high and $1.4^{\circ}$ wide. The lines that made up both sizes of letters and premasks were $0.3^{\circ}$ thick.

Stimulus letters and premasks were presented with their centers at the points of an imaginary hexagon, with each center about $5.75^{\circ}$ 
from fixation. Premasks and offset letters were always presented at the top, lower-left, and lower-right points of the hexagon, and onset letters were presented at the bottom, upper-left, and upperright points.

Procedure. Each subject was tested in a single session that lasted about $50 \mathrm{~min}$. The session consisted of four identical blocks of 128 trials. The first block was preceded by 20 randomly selected warmup trials, and subsequent blocks were each preceded by four randomly selected warmup trials.

As in the procedure of Yantis and Jonides (1984), each trial began with a 1-sec presentation, in the center of the display, of the target letter for that trial. This target letter was about $1.5^{\circ}$ high and $0.9^{\circ}$ wide, and it was drawn with lines of minimal thickness (less than $0.05^{\circ}$ ). One-half second after the offset of the target letter, a fixation point appeared in the center of the display, and the premasks appeared at the top, lower-left, and lower-right points of the imaginary hexagon. One second after the appearance of the fixation point and premasks, a single onset stimulus appeared at one of the three empty corners of the hexagon, and lines were removed from the premasks to leave either one or three offset letters. (When only one offset letter was presented, the other two premasks disappeared completely.) The display of letters remained on the screen until the subject made a keypress response, at which time accuracy feedback was given for $600 \mathrm{msec}$ following correct responses and for $1,200 \mathrm{msec}$ following errors. The next trial began after an intertrial interval of about $500 \mathrm{msec}$.

Within each block, half of the trials had two letters in the display and half had four letters. For each display size, half of the trials had a single target letter present, and the other half did not. In twoletter displays (one onset letter and one offset), the target was equally likely to be the offset letter or the onset letter. In four-letter displays (one onset letter and three offset), the target was equally likely to be any of the four letters, so it was an offset letter three times as often as it was an onset letter. These probabilities were used to avoid giving subjects any incentive to voluntarily pay attention to the onset transient letter, as discussed by Yantis and Jonides (1984)

\section{Results and Discussion}

Average reaction time (RT) and percentage of correct responses were computed for each subject and condition. Averages of these values as a function of display size and target type are shown in Table 1.

Display size had a 26-msec effect for onset-transient targets, and this effect was highly reliable in an analysis

Table 1

Mean Reaction Time (RT) (in msec) and Percentage of Correct Responses (PC) as a Function of Display Size and Target Location in Experiments 1 and 2

\begin{tabular}{|c|c|c|c|c|c|c|}
\hline \multirow[b]{3}{*}{ Display Size } & \multicolumn{6}{|c|}{ Target Type } \\
\hline & \multicolumn{2}{|c|}{ Onset Transient } & \multicolumn{2}{|c|}{ Offset Transient } & \multicolumn{2}{|c|}{ No Target } \\
\hline & RT & $\mathbf{P C}$ & RT & PC & RT & PC \\
\hline \multicolumn{7}{|c|}{ Experiment 1} \\
\hline 2 letters & 612 & 95 & 641 & 94 & 704 & 94 \\
\hline 4 letters & 638 & 94 & 686 & 95 & 773 & 93 \\
\hline Difference & 26 & 1 & 45 & -1 & 69 & 1 \\
\hline \multicolumn{7}{|c|}{ Experiment 2} \\
\hline 2 letters & 652 & 97 & 689 & 95 & 752 & 96 \\
\hline 4 letters & 661 & 96 & 735 & 94 & 812 & 96 \\
\hline Difference & 9 & 1 & 46 & 1 & 60 & 0 \\
\hline
\end{tabular}

that included the additional factors of trial block and letter size $[F(1,30)=7.9, p<.01]$. Thus, onset-transient targets did not pop out of a background of offset-transient distractors when the latter were produced by a sufficient number of offset transients. This finding supports the position that overall display change is an important determinant of attentional control, and it disconfirms the position that onsets are fully dominant over offsets in the competition for attention.

To compare the results with onset- and offset-transient targets, additional analyses were conducted on the targetpresent RT and percentage-of-correct-responses data with factors of target transients (onset vs. offset), display size, letter size, and trial block. As expected, practice produced a significant effect of trial block in both analyses, but this factor was not involved in any interactions. Onset-transient targets were detected $39 \mathrm{msec}$ faster than offset-transient targets $[F(1,30)=50, p<.01]$, and, on average, targets were detected $36 \mathrm{msec}$ faster in displays of two letters than of four letters $[F(1,30)=44, p<: 01]$. Although the effect of display size was substantially larger for offset-transient targets $(45 \mathrm{msec})$ than for onsettransient targets ( $26 \mathrm{msec}$ ), this interaction was only marginally significant $[F(1,30)=3.02, p<.10]$. Thus, there is only weak evidence that onset-transient targets attract attention better than do offset-transient targets with these premasks. The results of the analysis of percentage of correct responses preclude any interpretation of even this weak interaction, however, because the effect of display size on percentage of correct responses was significantly larger for onset- than for offset-transient targets $[F(1,30)$ $=6.54, p<.02]$. Although this interaction was small, it was present in 19 of 31 subjects (one tie), and it was also highly significant in an analysis using the commonly recommended arcsin transformation of percentage of correct responses (Murdock \& Ogilvie, 1968). Thus, the RT effect that suggests better attention-attracting power for onset-transient targets could well be due to speed-accuracy trade-offs, especially because even small accuracycriterion fluctuations can have large effects on RT when accuracy is near $100 \%$ (Pachella, 1974).

The factorial analyses of the target-present data also revealed an interaction of letter size and target transients in the RT data $[F(1,30)=6.53, p<.02]$. With onsettransient targets, responses were $20 \mathrm{msec}$ faster to large letters than to small ones, and this difference was significant $(p<.02)$ in the analysis that included only onsettransient targets. With offset-transient targets, there was essentially no effect of letter size (responses were $3 \mathrm{msec}$ slower to large letters than to small ones), and the same pattern was observed in target-absent trials.

With respect to the question of how transients attract visual attention, the main finding of the present study is that unique onset transients may not attract attention when substantial numbers of offset transients also occur. Both types of transients probably attract attention to some ex- 
tent, so offset transients may sometimes provide too much competition for onset transients to receive attentional priority.

\section{EXPERIMENT 2}

Before concluding that the lack of popout in Experiment 1 was due to the extra offset transients provided by the augmented premask (Figure 1B), it is necessary to consider the possibility that popout did not occur for some other reason. Popout is a notoriously sensitive phenomenon (e.g., Duncan, 1983), and it is possible that a critical detail of our apparatus or procedure was responsible for the lack of popout in Experiment 1. A second experiment was therefore undertaken to replicate Experiment 1 using the premask of Yantis and Jonides (1984), shown in Figure 1 A.

\section{Method}

The subjects were 35 new individuals recruited from the same subject pool used in the previous experiment. The same apparatus and procedure were used, with the only change being the form of the premask.

\section{Results and Discussion}

Table 1 shows the average RT and percentage of correct responses as a function of display size and target type. The 9 msec effect of display size with onset-transient targets did not approach significance $[F(1,34)=2.03$, $p>.15]$, so it seems reasonable to conclude that the onset-transient targets popped out of the display with these premasks.

Whether or not we accept the null hypothesis regarding the effect of display size with onset-transient targets, the change in the pattern of results from Experiment 1 clearly indicates the importance of the number of offset transients. As a result of the change in the premasks, the effect of display size had become clearly larger for offsetthan for onset-transient targets $[F(1,34)=12.2$, $p<.01]$.

Analyses across the two experiments provide further support for the interpretation of differences due to the premasks. ${ }^{3}$ Consistent with the view that the extra offset transients in Experiment 1 competed with onset transients for attention, the difference between onset- and offsettransient targets was smaller in Experiment 1 than in Experiment $2[F(1,60)=5.98, p<.02]$. Furthermore, in an analysis that included only onset-transient targets, the effect of display size was larger in Experiment 1 than in Experiment 2, though this effect was only marginally significant $[F(1,60)=3.33, p<.10]$.

\section{CONCLUSION}

Onset-transient targets may popout of a background of offset-transient distractors. This popout can be eliminated, however, when the offset-transient stimuli produce a to- tal visual change (offsets plus onsets) similar to the onsettransient stimuli. For example, when offset-transient distractors were produced by removing about six lines from the premask (Experiment 1), detection of onset-transient targets was affected (i.e., popout was eliminated). This result suggests that visual attention may be directed, at least to some extent, by offset transients as well as by onset transients. Thus, we must take issue with the suggestion of Jonides and Yantis (1988) that onset transients are unique in their ability to command attentional responses.

The present results are consistent, however, with the suggestion that onset transients are more powerful than offset transients in controlling attention. Even in Experiment 1 , in which offset distractors were created with more total display change than were onset flankers, the onset flankers interfered more with the detection of targets. Although this conclusion must be tempered somewhat by the lack of an externally validated metric for comparing offsets with onsets, it seems likely that onsets have the larger effects on attention, even though offsets do have some control as well.

Once it is accepted that offset-transients have some power to attract attention, a small puzzle arises. Consider what happens when a premask disappears totally from a display, leaving no residual stimulus. This event produces the maximum total number of offsets from the premask, and it might therefore be expected to be the most effective attractor of attention that it is possible to construct using offset transients. Clearly, however, disappearing premasks did not interfere more with target detection than did premasks that changed into letters. If they had, subjects would actually have been slower to find targets in displays of two letters than in displays of four letters, because the former contained two of the disappearing premasks that, by this hypothesis, should have been maximally effective distractors. The question, then, is why stimuli with more offsets (disappearing premasks) are less effective distractors than stimuli with fewer offsets (premasks that change into letters).

There are at least two possible solutions to this apparent puzzle. One is that offset-transients do not attract attention to a region in visual space, but rather attract attention to a stimulus object. When no stimulus object remains, offset transients might have no distracting effect. The other possible explanation is that offset-transients do attract attention to a region in visual space, but that attention can move away from that region immediately if it contains no stimulus to be analyzed. In this view, transients may misdirect attention with little or no cost as long as negligible time is spent in the processing of empty locations and in the shifting of attention between locations. The assumption of instantaneous attentional movement seems implausible, but this model still merits some consideration given the controversy over how attention moves in visual space (Eriksen \& Murphy, 1987). Further research will be necessary to discriminate among the possible mechanisms of offset-transient effects. 


\section{REFERENCES}

Bartram, D. (1978). Post-iconic visual storage: Chunking in the reproduction of briefly displayed visual patterns. Cognitive Psychology, 10, 324-355.

Breitmeyer, B. G., GANZ, L. (1976). Implications of sustained and transient channels for theories of visual pattern masking, saccadic suppression, and information processing. Psychological Review, 83, 1-36.

Duncan, J. (1981). Directing attention in the visual field. Perception \& Psychophysics, 30, 90-93.

DUNCaN, J. (1983). Category effects in visual search: A failure to replicate the "oh-zero" phenomenon. Perception \& Psychophysics, 34, 221-232.

DunCAN, J. (1984). Selective attention and the organization of visual information. Journal of Experimental Psychology: General, 113, 501-517.

Eriksen, C. W., Hoffman, J. E. (1972). Some characteristics of selective attention in visual perception determined by vocal reaction time. Perception \& Psychophysics, 11, 169-171.

ErIxsen, C. W., \& MUrPhY, T. D. (1987). Movement of attentional focus across the visual field: A critical look at the evidence. Perception \& Psychophysics, 42, 299-305.

Hoffman, J. E., Nelson, B., \& Houck, M. R. (1983). The role of attentional resources in automatic detection. Cognitive Psychology, $15,379-410$.

James, W. (1890). Principles of psychology. New York: Holt.

Johnston, W. A., DARK, V. J. (1986). Selective attention. Annual Review of Psychology, 37, 43-75.

JONIDES, J. (1981). Voluntary versus automatic control over the mind's eye's movement. In J. Long \& A. Baddeley (Eds.), Attention and performance. (Vol. 9, pp. 187-203). Hillsdale, NJ: Erlbaum.

JoNIDES, J., \& YANTIS, S. (1988). Uniqueness of abrupt visual onset in capturing attention. Perception \& Psychophysics, 43, 346-354.

Kahneman, D., \& Treisman, A. M. (1984). Changing views of attention and automaticity. In R. Parasuraman \& D. R. Davies (Eds.), Varieties of attention (pp. 29-61). New York: Academic Press.

LABerge, D. (1983). Spatial extent of attention to letters and words. Journal of Experimental Psychology: Human Perception \& Performance, 9, 371-379.

Murdock, B. B., JR., \& OGILvIE, J. C. (1968). Binomial variability in short-term memory. Psychological Bulletin, 70, 256-260.

Pachella, R. G. (1974). The interpretation of reaction time in information-processing research. In B. Kantowitz (Ed.), Human in- formation processing: Tutorials in performance and cognition (pp. 4182). Hillsdale, NJ: Erlbaum.

Phillips, W. A., Singer, W. (1974). Function and interaction of on and off transients in vision. I. Psychophysics. Experimental Brain Research, 19, 493-506.

RUMelHaRT, D. E. (1970). A multicomponent theory of the perception of briefly exposed displays. Journal of Mathematical Psychology, 7, 191-218.

RUmelharT, D. E. (1971). A multicomponent theory of confusion among briefly exposed alphabetic characters. (Tech. Rep. No. 22). San Diego: University of California, Center for Human Information Processing.

SCHILlER, P. H. (1984). The connections of the retinal on and off pathways to the lateral geniculate nucleus of the monkey. Vision Research, 24, 923-932.

SHAw, M. L., SHAw, P. (1977). Optimal allocation of cognitive resources to spatial location. Joumal of Experimental Psychology: Human Perception \& Performance, 3, 201-211.

Stelmach, L. B., Bourassa, C. M., \& Di Lollo, V. (1984). Detection of stimulus change: The hypothetical roles of visual transient responses. Perception \& Psychophysics, 35, 245-255.

YANTIS, S., \& Jonides, J. (1984). Abrupt visual onsets and selective attention: Evidence from visual search. Joumal of Experimental Psychology: Human Perception \& Performance, 10, 601-621.

\section{NOTES}

1. The five-to-two ratio is not meant to be taken as the only possible psychological representation of the total change, but merely as a plausible estimate. The point is that, for these premasks, the change would be larger for onset than for offset letters in any reasonable metric.

2. This article will not attempt to settle the issue of whether onset and offset transients are equally effective in attracting attention, but only whether onset transients are fully dominant over offset transients. The former issue is very difficult to resolve definitively at this time, because it requires as yet unavailable techniques for equating the psychological representations of the changes involved in onsets and offsets.

3. Only the first 31 subjects from Experiment 2 were used, so that a simple, equal-cell-size ANOVA could be performed.

(Manuscript received July 11, 1988;

revision accepted for publication December 5, 1988.) 